\title{
Nodular scleritis and granulomatous polyangiitis (Wegener) mimicking tuberculosis
}

\author{
Esclerite nodular e poliangiite granulomatosa \\ (Wegener) mimetizando tuberculose
}

Cybelle Moreno Luize Franco ${ }^{1}$, Grazielly Martins Peixoto de Oliveira², Tânia Sales de Alencar Fidelix³ , Luiz Antônio Vieira ${ }^{4}$, Virginia Fernandes Moça Trevisani ${ }^{5}$

\begin{abstract}
Granulomatous polyangiitis is a systemic disease that may affect any organ, with a predilection for the upper respiratory tract, lungs and kidneys. This article aims to report a case of a patient with atypical nodular scleritis as the initial manifestation of granulomatous polyangiitis (Wegener), mimicking a case of tuberculosis. The patient presented ocular hyperemia and lower progressive visual acuity for 1.5 years, followed by eye pain for two months. The patient had subpleural nodules with soft tissue density, increased pulmonary lymph nodes and discrete bilateral pleural thickening, with negative alcohol-resistant acid bacilli (BAAR). The histological diagnosis revealed a granulomatous vasculitis suggestive of non-infectious vasculitis (granulomatous polyangiitis). Cyclophosphamide pulse therapy was initiated.
\end{abstract}

Keywords: Wegener granulomatosis; Granulomatous polyangiitis; Vasculitis; Scleritis; Pulse therapy; Case reports

\section{RESUMO}

Poliangiite granulomatosa é uma doença sistêmica que afeta qualquer órgão, com predileção pelo trato respiratório superior, pulmões e rins. Este artigo tem como objetivo relatar um caso atípico de uma paciente com esclerite nodular como manifestação inicial da poliangiite granulomatosa (Wegener), mimetizando um quadro de tuberculose. A paciente apresentou hiperemia ocular e baixa acuidade visual progressiva por 1,5 anos, seguido por dor ocular por dois meses. A paciente possuía nódulos subpleurais com densidade de partes moles, linfonodomegalia em janela aorto-pulmonar e espessamento pleural bilateral discreto, negativo para bacilos álcool-ácido resistentes (BAAR). O diagnóstico histológico revelou uma vasculite granulomatosa sugestiva de vasculite não infecciosa (poliangiite granulomatosa). Foi iniciada pulsoterapia com ciclofosfamida.

Descritores: Granulomatose de Wegener; Poliangiite granulomatosa; Vasculite; Esclerite; Pulsoterapia; Relatos de casos

\footnotetext{
${ }^{1}$ External Diseases and Medical-Surgical Cornea Unit, Federal University of São Paulo, São Paulo/SP, Brazil.

${ }^{2}$ External Diseases and Medical-Surgical Cornea Unit, Sorocaba Eye Hospital, Sorocaba/SP, Brazil.

${ }^{3}$ Professor of Ophthalmology, Federal University of São Paulo, São Paulo/SP, Brazil.

${ }^{4}$ Federal University of São Paulo, São Paulo/SP, Brazil.

${ }^{5}$ Professor of Rheumatology, University of Santo Amaro, São Paulo/SP, Brazil; Professor of Emergency Medicine and Evidence-Based Medicine, Federal University of São Paulo, São Paulo/SP, Brazil.
}

Institution: Federal University of São Paulo, São Paulo/SP, Brazil.

Os autores declaram não haver conflitos de interesse

Received for publication 20/01/2013 - Accepted for publication 06/01/2014. 


\section{INTRODUCTION}

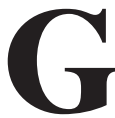
ranulomatosis with polyangiitis (GPA), formerly known as Wegener's granulomatosis ${ }^{1}$, is a systemic disease of unknown aetiology that can affect several organs, especially the upper respiratory tract, lungs, and kidneys. It is characterised by granulomatous inflammation, tissue necrosis, and various degrees of small and medium calibre vasculitis ${ }^{2}$.

Clinical evaluation, the disease's association with antineutrophil cytoplasmic antibody (ANCA), and a positive biopsy of affected tissues are important for diagnosis. Ocular involvement is observed in $50-60 \%$ of cases, and it persists throughout the patient's life in up to $87 \%$ of cases. This can be the sole manifestation of the disease in $8-16 \%$ of patients ${ }^{3}$.

Unexplained inflammatory orbital disease, scleritis, peripheral ulcerative keratitis, scarring conjunctivitis, nasolacrimal duct stenosis, retinal vascular occlusion, and/or uveitis should raise suspicion of the disease. A detailed clinical examination, laboratory and imaging tests, and histological evaluation are essential for diagnosis and to rule out diseases with similar features. Treatment with cytotoxic and immunosuppressive agents has significantly improved the prognosis of GPA, which used to have a high mortality rate before the advent of these therapies ${ }^{3,4}$.

\section{Case Report}

R.G.S., a 60-year-old white, female, married, retired patient from São Paulo/SP, Brazil, attended the outpatient clinic of the External Diseases and Cornea Unit of the Department of Ophthalmology of the Federal University of São Paulo with hyperaemia in the right eye and progressively lower visual acuity starting 1.5 years earlier. The patient also reported eye pain starting two months earlier. She reported suffering from high blood pressure and diabetes mellitus for 20 years and having undergone hysterectomy due to uterine cancer in 1998. Best-corrected visual acuity was 20/32 in the right eye and 20/20 in the left eye. Anterior biomicroscopy found bulbar conjunctival hyperaemia, scleral thinning in the inferior nasal quadrant, a clear cornea with dellen in the inferior nasal quadrant, no anterior chamber reaction, and a transparent lens in the right eye (Figure 1). Intraocular pressure

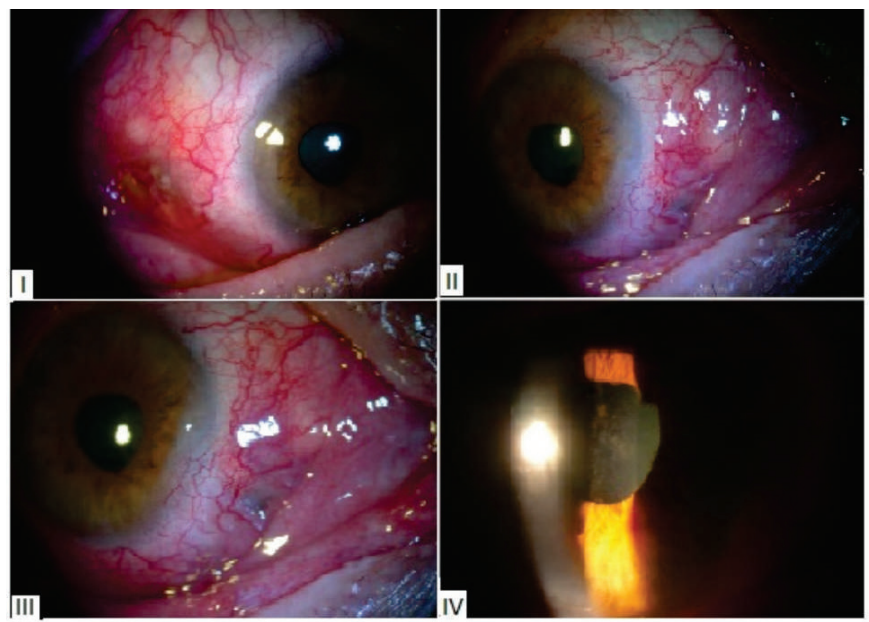

Figure 1: I, II, II - Scleral thinning and corneal dellen in the inferior nasal quadrant. IV - No anterior chamber reaction. was $12 \mathrm{mmHg}$ for both eyes at $8 \mathrm{am}$. Fundus examination found a physiologic cup and no oedema, retinal haemorrhage, or signs of vasculitis in both eyes.

The only altered laboratory tests were blood glucose (190 $\mathrm{mg} / \mathrm{dL}$ ) and AST (50 U/L), while ANA, FR, anti-DNA, anti-SSA/ SSB/DNA/Sm/RNP, C3, C4, CH-50, immunoglobulins (IgA/G/ $\mathrm{M})$, cryoglobulins, and hepatitis $\mathrm{B}$ and $\mathrm{C}$ antibodies were normal. ANCA was negative.

The diagnostic hypothesis was keratoscleritis in the right eye. Oral prednisone, at a dose from varying from 20 to $60 \mathrm{mg} /$ day, and oral azathioprine $100 \mathrm{mg}$ /day were prescribed.

After 13 months of treatment, fundus examination of the right eye found a whitish, granulomatous, dense inferior peripheral subretinal lesion associated with serous retinal detachment with subretinal fluid extending to the foveal region, as well as vitreous opacities and choroidal detachments in the inferior and superior nasal quadrants. Ultrasound imaging showed wall thickening in the posterior pole, and biomicroscopy found scleritis with perilimbal scleral thinning and a deformed limbus.

Chest computed tomography (CT) found subpleural nodules of soft tissue density, lymphadenopathy in the aortopulmonary window, and mild bilateral pleural thickening (Figure 2).

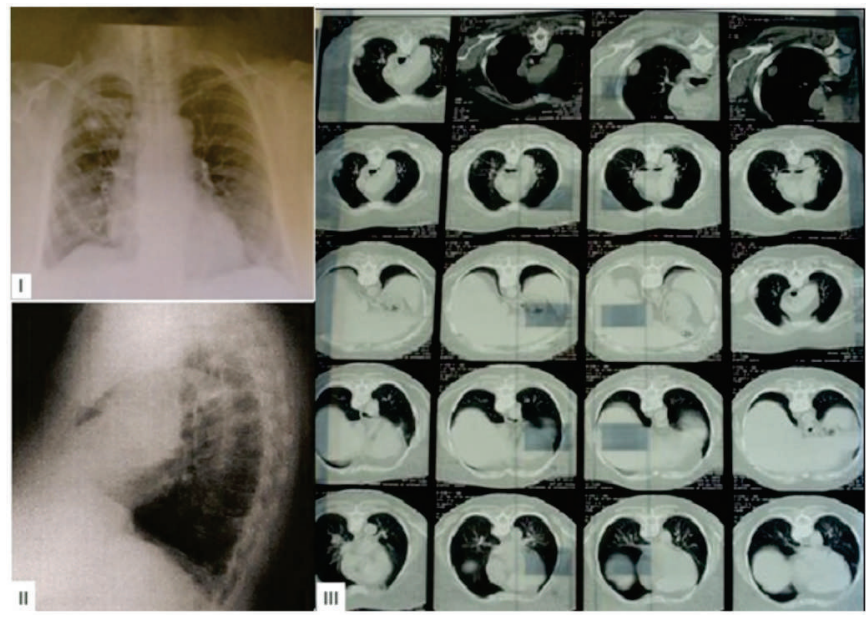

Figure 2: - Chest radiograph and CT scan showing subpleural nodules of soft tissue density, lymphadenopathy in the aortopulmonary window, and mild bilateral pleural thickening.

A transpulmonary biopsy revealed chronic granulomatous pleuritis with necrosis. The tuberculosis skin test (PPD) was 0 $\mathrm{mm}$; it should be noted that the patient was immunosuppressed with prednisone and azathioprine, as well as being elderly and having uncontrolled diabetes mellitus. Bacterioscopy found no acid-alcohol-fast bacilli or fungi (no absolute histological criteria suggesting sarcoidosis). The patient was treated against tuberculosis (rifampin, isoniazid, pyrazinamide, and ethambutol [RHZE]) by the pulmonology clinic at the same university due to the CT and pathology results. Treatment with azathioprine was discontinued. The patient received treatment for tuberculosis for nine months; nonetheless, her pulmonary symptoms worsened and her ocular symptoms failed to improve. The pulmonary nodule grew, and a small pleural effusion was observed six months after the end of treatment. As there was no improvement after treatment for tuberculosis, a nodulectomy was performed on the upper pulmonary lobe to clarify the 
aetiology of the disease. The histological diagnosis was granulomatous vasculitis suggestive of non-infectious vasculitis (GPA), thus dismissing the previous diagnosis of tuberculosis. Treatment with cyclophosphamide pulse therapy was initiated. The patient received 12 cyclophosphamide pulses, in addition to oral azathioprine $150 \mathrm{mg}$ /day and oral prednisone at doses of 20 to $60 \mathrm{mg} / \mathrm{day}$. After the cyclophosphamide treatment was completed, the scleral lesion recurred while the patient was using azathioprine and phasing out the oral corticosteroids. Thus, azathioprine was replaced by mycophenolate sodium. From that moment onwards, the scleral injury remained stable and the underlying disease was controlled, suggesting the diagnosis of GPA. The maintenance regimen was mycophenolate sodium 1.44 $\mathrm{g}$ daily and prednisone $20 \mathrm{mg}$ daily.

Fundus examination continued to show retinal detachment in the right eye, with a final visual acuity of hand motion, and unchanged visual acuity in the left eye (20/20).

\section{Discussion}

GPA is a disease of unknown aetiology and was first described in 1937. It is one type of ANCA-associated vasculitis. ANCA can be directed to proteinase-3 (PR3-ANCA) and myeloperoxidase (MPO-ANCA) and is highly prevalent in GPA, microscopic polyangiitis, and Churg-Strauss syndrome ${ }^{5}$.

GPA is a multifocal inflammatory disease that most commonly affects the upper and lower respiratory tract and the kidneys ${ }^{6}$. Multiple organ involvement is associated with a poorer prognosis, and its mortality rate used to reach $80 \%$ in the first year of disease ${ }^{7}$. In the early 1970s, the introduction of drugs such as cyclophosphamide combined with glucocorticoids changed the course of the disease, which ceased to be highly lethal, and remission became possible. However, cases refractory to medication are frequent and, after achieving remission, relapses associated with attempts to discontinue or reduce the medication are common. As a consequence, the side effects of therapies increase the morbidity and mortality associated with the disease ${ }^{8,9}$.

In the case presented here, GPA presented with nodular scleritis. In addition to GPA, rheumatoid arthritis, systemic lupus erythematosus, relapsing polychondritis, and inflammatory bowel disease should also be investigated in similar cases. Necrotising scleritis is more common in GPA; its prognosis is worse and it frequently causes visual impairment ${ }^{5}$.

Up to $58 \%$ of patients with GPA have ophthalmic manifestations. In a study of 158 patients with GPA, 52\% had eye disease (scleral involvement in 10\%), of whom $8 \%$ developed visual loss ${ }^{8}$. In another review of $140 \mathrm{GPA}$ cases, $29 \%$ presented ocular disease. Orbital involvement was the most common (15\%), followed by scleral $(7 \%)$, episcleral $(3.5 \%)$, corneal $(8 \%)$, and nasolacrimal $(7 \%)$ involvement ${ }^{10}$.

In a study of 47 patients with GPA, 57.4\% presented with systemic disease and then developed ocular disease. Only $6.3 \%$ of patients presented eye disease first, followed by systemic disease. Another $6.3 \%$ of patients had eye disease first, but systemic disease was found during diagnostic examination. Overall, isolated ocular involvement persisted in $30 \%$ of patients after ten years of follow-up. In all groups, necrotising scleritis was the most frequent presentation ${ }^{11}$.

The diagnosis of GPA requires positive ANCA, which did not occur in the present case. However, when the illness is "limited" to the facial sinuses and orbit, ANCA may be negative in up to $50 \%$ of cases; a biopsy of affected tissues may be required to determine the diagnosis ${ }^{12}$.

There appears to be an atypical course in cases of limited GPA with negative ANCA; diagnosis usually takes longer and the disease has a better prognosis, except for the tissue damage resulting from delayed diagnosis ${ }^{13,14}$.

In Brazil, it is not standard procedure to start treatment for extrapulmonary tuberculosis when PPD testing is negative, since the Brazilian protocol includes a positive PPD test as a precondition for starting treatment. The incidence of pulmonary tuberculosis in the Brazilian population is still very high, and PPD testing is important in the screening for latent tuberculosis, as it is a simple test with a low cost. However, a positive PPD test is not required in some situations, such as diabetes mellitus, old age, or immunosuppression. Pulmonary nodules can establish the diagnosis of tuberculosis even in cases with a negative PPD test, and there are reports of patients with concomitant GPA and tuberculosis ${ }^{15}$. Studies show that the PPD test can be negative in $20-25 \%$ of immunocompetent patients with active pulmonary tuberculosis ${ }^{16,17}$; it can also be negative in patients with active ocular tuberculosis ${ }^{18}$. As widely reported in the literature, immunosuppressed patients can have a negative PPD test even in the presence of active pulmonary tuberculosis, e.g. when prednisone is used ${ }^{19-21}$. Recent international studies suggest that even if the PPD test is normal, pulmonary tuberculosis should be diagnosed and treated in symptomatic elderly patients or when imaging studies are altered ${ }^{22-25}$. Diabetes mellitus is another well-known cause of active pulmonary tuberculosis with a negative PPD test ${ }^{22-25}$. The patient presented here was immunosuppressed with prednisone and azathioprine, was elderly, and had uncontrolled diabetes mellitus at the time of PPD testing. Therefore, the diagnosis of pulmonary tuberculosis could not be based only on this test, since all these factors can lead to a false-negative result. The suggestive imaging tests, the epidemiology of the disease (with a high incidence in the region), the fact that the patient had uncontrolled diabetes mellitus (which increases the risk of developing the disease, whether symptomatic or asymptomatic, even with a negative PPD test), and the patient's age (elderly patients have higher risk of developing the disease, whether symptomatic or asymptomatic, even with a negative PPD test) were thus used as the basis for treatment against tuberculosis, in accordance with recent international studies. The diagnosis of pulmonary tuberculosis was later dismissed because the patient's pulmonary symptoms worsened and there was no improvement in ocular symptoms despite the treatment for tuberculosis, as well as the lung biopsy typical of GPA.

The treatment of GPA with corticosteroids and immunosuppressive agents has improved the prognosis of the disease, but morbidity and mortality are still high ${ }^{10}$. In this case report, treatment with cyclophosphamide clearly modified the prognosis, with significant improvement in ocular disease, suggesting a diagnosis of GPA. Pulse therapy with cyclophosphamide is effective in improving renal function, as well as joint and ocular symptoms ${ }^{26}$.

Anti-tumour necrosis factors have been described as an alternative in the treatment of GPA, with fewer side effects. Infliximab and etanercept have been effective in the treatment of chronic inflammatory diseases resistant to usual immunosuppressive therapy ${ }^{27}$. Infliximab is superior to etanercept, and there are no reports on adalimumab ${ }^{28}$. 
There are also reports of GPA treated with rituximab, an anti-CD20 agent (B-cells), in cases of GPA refractory to cyclophosphamide. The reports are encouraging in terms of remission and side effects when compared with cyclophosphamide ${ }^{4,29,30}$.

This case report highlights aspects that are relevant to the assessment of necrotising scleritis. The ophthalmic diagnosis should always include an investigation of systemic diseases. Furthermore, early treatment with appropriate medication can be crucial to preserve visual acuity. GPA is usually refractory to traditional treatment, and other immunobiological drugs can be used to preserve the involved organs and reduce comorbidities due to the adverse effects of therapy.

\section{References}

1. Jennette JC. Nomenclature and classification of vasculitis: lessons learned from granulomatosis with polyangiitis (Wegener's granulomatosis). Clin Exp Immunol. 2011;164 Suppl 1:7-10. Review.

2. Stone JH, Hoffman GS. Wegener's granulomatosis and lymphomatoid granulomatosis. In: Hochbert MC, Silman AJ, Smolen JS, Weinblatt ME, Weisman MH editors. Rheumatology. 3rd ed. Edinburgh, UK: Mosby; 2003. p.1624-34.

3. Pakrou N, Selva D, Leibovitch I. Wegener's granulomatosis: ophthalmic manifestations and management. Semin Arthritis Rheum. 2006;35(5):284-92. Review.

4. Huerva V, Sanchez MC, Traveset A, Jurjo C, Ruiz A. Rituximab for peripheral ulcerative keratitis with wegener granulomatosis. Cornea. 2010;29(6):708-10.

5. Kallenberg CG. Pathophysiology of ANCA-associated small vessel vasculitis. Curr Rheumatol Rep. 2010;12(6):399-405. Review.

6. Said MS. Upper respiratory tract symptoms, renal involvement and vasculitis: a case report and review of wegener granulomatosis. J Clin Med Res. 2010;2(4):189-93.

7. Walton EW. Giant-cell granuloma of the respiratory tract (Wegener's granulomatosis). Br Med J. 1958;2(5091):265-70.

8. Hoffman GS, Kerr GS, Leavitt RY, Hallahan CW, Lebovics RS, Travis WD, et al. Wegener granulomatosis: an analysis of 158 patients. Ann Intern Med. 1992;116(6):488-98.

9. Guillevin L, Cordier JF, Lhote F, Cohen P, Jarrousse B, Royer I, et al. A prospective, multicenter, randomized trial comparing steroids and pulse cyclophosphamide versus steroids and oral cyclophosphamide in the treatment of generalized Wegener's granulomatosis. Arthritis Rheum. 1997;40(12):2187-98.

10. Bullen CL, Liesegang TJ, McDonald TJ, DeRemee RA. Ocular complications of Wegener's granulomatosis. Ophthalmology. 1983;90(3):279-90.

11. Harper SL, Letko E, Samson CM, Zafirakis P, Sangwan V, Nguyen $\mathrm{Q}$, et al. Wegener's granulomatosis: the relationship between ocular and systemic disease. J Rheumatol. 2001;28(5):1025-32.

12. Thorne JE, Jabs DA. Ocular manifestations of vasculitis. Rheum Dis Clin North Am. 2001;27(4):761-79, vi. Review.

13. Hsu JT. Limited form of Wegener's granulomatosis. Chest. 1976;70(03):384-5.

14. Ishii T, Bandoh S, Fujita J, Horiike A, Tojo Y, Kubo A, et al. [A case of the limited from of Wegener's granulomatosis without cANCA]. Nihon Kokyuki Gakkai Zasshi. 2003;41(11):834-9. Review. Japanese.

15. Molinari L, Melamud JI, Ferrari L, Landi P, Semeniuk G, Quadrelli SA. [Wegener's granulomatosis and tuberculosis. A bad combination]. Medicina (B Aires). 2009;69(6):640-2. Spanish.

16. Fietta A, Meloni F, Cascina A, Morosini M, Marena C, Troupioti P, et al. Comparison of a whole-blood interferon-gamma assay and tuberculin skin testing in patients with active tuberculosis and individuals at high or low risk of Mycobacterium tuberculosis infection. Am J Infect Control. 2003;31(6):347-53.
17. Pai M, Riley LW, Colford JM Jr. Interferon-gamma assays in the immunodiagnosis of tuberculosis: a systematic review. Lancet Infect Dis. 2004;4(12):761-76. Review.

18. Ishihara M, Ohno S. [Ocular tuberculosis]. Nihon Rinsho. 1998;56(12):3157-61. Review. Japanese.

19. Bélard E, Semb S, Ruhwald M, Werlinrud AM, Soborg B, Jensen FK, et al. Prednisolone treatment affects the performance of the QuantiFERON gold in-tube test and the tuberculin skin test in patients with autoimmune disorders screened for latent tuberculosis infection. Inflamm Bowel Dis. 2011;17(11):2340-9.

20. Tavast E, Tuuminen T, Pakkanen SH, Eriksson M, Kantele A, Järvinen A, et al. Immunosuppression Adversely Affects TST but Not IGRAs in Patients with Psoriasis or Inflammatory Musculoskeletal Diseases. Int J Rheumatol. 2012;2012:381929.

21. Lopes DM, Pinheiro VG, Monteiro HS, Queiroz JA, Madeira Ldos S, Lopes MM. Diagnosis and treatment of latent tuberculosis in patients with chronic inflammatory diseases: use of TNF-alphatargeting biological products. J Bras Pneumol. 2011;37(3):30816. English, Portuguese.

22. Fujita Y, Ogata H, Yano I. Clinical evaluation of serodiagnosis of active tuberculosis by multiple-antigen ELISA using lipids from Mycobacterium bovis BCG Tokyo 172. Clin Chem Lab Med. 2005;43(11):1253-62.

23. Christopoulos AI, Diamantopoulos AA, Dimopoulos PA, Goumenos DS, Barbalias GA. Risk factors for tuberculosis in dialysis patients: a prospective multi-center clinical trial. BMC Nephrol. 2009;10:36.

24. Jung JY, Lim JE, Lee HJ, Kim YM, Cho SN, Kim SK, et al. Questionable role of interferon-ã assays for smear-negative pulmonary TB in immunocompromised patients. J Infect. 2012;64(2):188-96.

25. Harris TG, Sullivan Meissner J, Proops D. Delay in diagnosis leading to nosocomial transmission of tuberculosis at a New York City health care facility. Am J Infect Control. 2013;41(2):155-60.

26. Pavelka K Jr, Dostal C, Rossmann P, Kraus H, Matousovic K, Vrabec J. Wegener's granulomatosis with bilateral necrotizing scleritis, polyarthritis and renal failure efficiently treated with immunosuppressive therapy. Clin Rheumatol. 1986;5(1):112-7.

27. Aeberli D, Oertle S, Mauron H, Reichenbach S, Jordi B, Villiger PM. Inhibition of the TNF-pathway: use of infliximab and etanercept as remission-inducing agents in cases of therapy-resistant chronic inflammatory disorders. Swiss Med Wkly. 2002; 132(29-30):414-22.

28. Nizam S, Johnstone A, Green M, Gough A. Necrotising scleritis and connective tissue disease-three cases and a review. Clin Rheumatol. 2009;28(3):339-41.

29. Onal S, Kazokoglu H, Koc A, Yavuz S. Rituximab for remission induction in a patient with relapsing necrotizing scleritis associated with limited Wegener's granulomatosis. Ocul Immunol Inflamm. 2008;16(5):230-2.

30. Taylor SR, Salama AD, Joshi L, Pusey CD, Lightman SL. Rituximab is effective in the treatment of refractory ophthalmic Wegener's granulomatosis. Arthritis Rheum. 2009;60(5):1540-7.

\section{Corresponding author:}

Cybelle Moreno Luize Franco

Rua Nabeck Shiroma, 210, Sorocaba/SP, Brazil, CEP 18031-060

E-mail: cyluize@yahoo.com.br 